\title{
The upper crust of the Eastern Tennessee Seismic Zone: insights from potential fields inversion
}

\author{
Authors: Enrico Brandmayr ${ }^{1}$ and Gordana Vlahovic ${ }^{2}$ \\ ${ }^{1}$ Center for Research Excellence in Science and Technology, North Carolina Central University, \\ Durham, North Carolina, USA. \\ ${ }^{2}$ Department of Environmental, Earth and Geospatial Sciences, North Carolina Central \\ University, Durham, North Carolina, USA. (email: gvlahovic@ nccu.edu) \\ Corresponding author: Enrico Brandmayr (ebrandma@nccu.edu), Center for Research \\ Excellence in Science and Technology, Room 1248, Mary Townes Science Complex, North \\ Carolina Central University, 1801 Fayetteville Street Durham, NC 27707, USA
}




\section{Abstract}

The study investigates the crustal structure of the eastern Tennessee seismic zone (ETSZ) by means of potential field inversion through the located Euler deconvolution method. Inversion of magnetic field data shows that the top of the magnetic basement ranges between 6 and $12 \mathrm{~km}$ depth in the Valley and Ridge physiographic province while it is shallower (less than $2 \mathrm{~km}$ depth) and locally outcropping in the Blue Ridge and Cumberland Plateau provinces. The estimated depth to the top of the magnetic basement is in general agreement with existing sedimentary cover maps of the broad study area. The inversion of gravity data is much more ambiguous, pointing to a generally deeper source, than magnetic data inversion. The findings support the interpretation of ETSZ seismicity as originating in basement structures not related to Appalachian orogeny and likely dating to Grenville age.

Keywords: ETSZ, NY-AL lineament, magnetic anomaly, gravity anomaly, depth to basement

\section{Introduction}

The ETSZ, located mainly in the Valley and Ridge province of the southern Appalachians (Fig. 1), is the second-most seismically active area in the eastern United States, after the New Madrid seismic zone, on the basis of energy release [Powell et al., 1994]. The ETSZ does not exhibit surface faulting, and the largest instrumentally recorded events, which occurred on 30 November 1974 near Maryville, Tennessee [Bollinger et al., 1976] and on 29 April 2003 near Fort Payne, Alabama [Dunn and Chapman, 2006], are of moderate magnitude (4.6 Mw), although the area generated damaging earthquakes in historical time [Bollinger, 1973]. These factors significantly hamper our ability in determining the seismogenic potential of the ETSZ. 


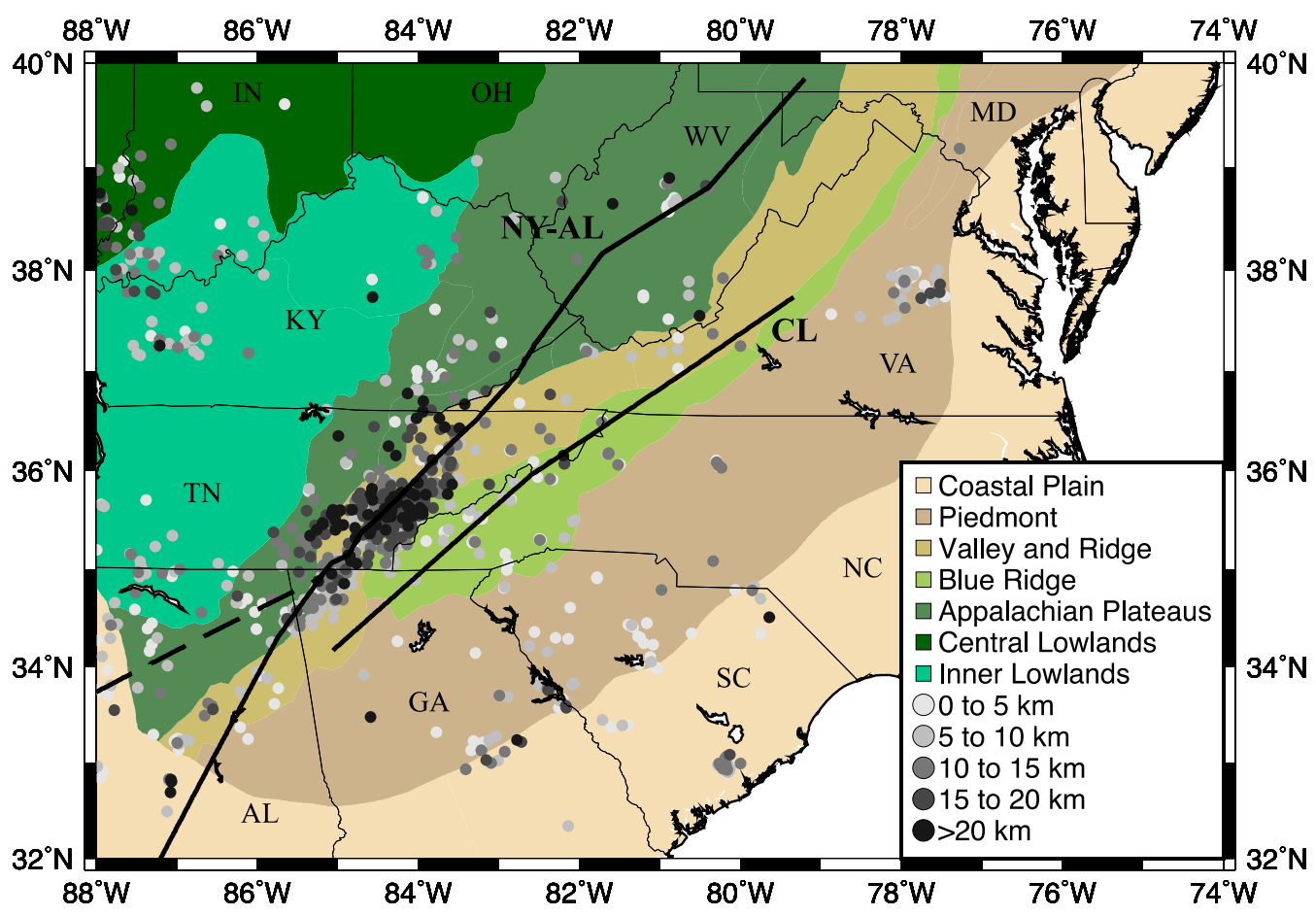

Figure 1. Map of the study area with geological provinces after Fenneman and Johnson [1946].

Gray dots are hypocenters reported in the CERI-University of Memphis catalogue from 1974 to 2014. Black lines denote New York-Alabama (NY-AL) and Clingman (CL) magnetic lineaments. Dashed black line denotes NY-AL lineament southern segment after Steltenpohl et al. [2010]. White rectangle encloses ETSZ. For color legend, refer to the online version of the paper.

Earthquakes occur at depths between 5 and $26 \mathrm{~km}$ [Vlahovic et al., 1998], concentrated between 8 and $15 \mathrm{~km}$, beneath the Paleozoic decollement. Thus, they are poorly related to surface geological features and have been attributed to basement faults not linked to any of the four stages of the Appalachian orogeny [e.g. Thomas, 2006]. 
The sedimentary cover is composed mainly of Cambrian to Lower Ordovician rocks deposited in a passive margin setting, as well as Middle Ordovician to Pennsylvanian rocks deposited on the Appalachian foreland during the Taconic and Alleghanian orogenic phases. Basement rocks are supposed to date back to Grenville age, although the position of the Grenville front in the region is unknown [Powell et al., 2014].

In addition to its complicated geology, the ETSZ is associated with a major magnetic lineament known as the NY-AL lineament, the tectonic significance of which remains controversial. This lineament marks the boundary between a spotty pattern of low and high anomalies associated with a granite-rhyolite province and Neoproterozoic mafic bodies to the northwest, and NE-trending magnetic lineaments of the Appalachian orogeny to the southeast. Interpretations about the tectonic role of the NY-AL lineament favor two options: 1) a collisional [King and Zietz, 1978] or post-collisional [Steltenpohl et al., 2010] intra-Grenville strike-slip fault, likely representing an age boundary within the Grenville tectonic province [Powell et al., 2014], or 2) the axis of anatectic melting following continental collision [Hopkins, 1995] during the Grenville orogeny. However, the hypocenters in the ETSZ are mainly located in a basement block, the Ocoee block [Johnston et al., 1985], which is delimited to the northwest by the NYAL magnetic lineament and to the southeast by the less prominent Clingman magnetic lineament. Steltenpohl et al. [2010] suggest that the Ocoee block could be composed of relatively nonmagnetic meta-sedimentary gneisses, similar to the Amish anomaly, of which it would represent a southward continuation.

Seismological and potential field data offer complementary information about the structure of the earth's interior. The intrinsic non-uniqueness of the inverse problem in geophysics makes their joint analysis and interpretation a very useful tool, especially in low- 
seismicity continental areas like the ETSZ. The present work focuses on potential field analyses using 3D Euler deconvolution, obtaining results consistent with some of the interpretations previously proposed. A companion paper describes the results of seismic noise tomography of the upper crust in the same study area.

\section{Methods}

The depth and the location of source rocks causing magnetic and gravity anomalies in the study area are estimated through 3D Euler deconvolution. We use a commercial software package based on the algorithm proposed by Reid et al. [1990], which is the three-dimensional implementation of the Euler's homogeneity equation described by Thompson [1982] for a twodimensional profile. The solution of the Euler's homogeneity equation for a certain potential field (F) is the linearization of a strongly non-linear problem that requires independent a priori assumptions on the geometry of the causative bodies. Its formulation in Cartesian coordinates is

$$
\left(x-x_{0}\right) \frac{\partial F}{\partial x}+\left(y-y_{0}\right) \frac{\partial F}{\partial y}+\left(z-z_{0}\right) \frac{\partial F}{\partial z}=N(B-F)
$$

where $\mathrm{N}$ is the structural index (SI, assuming integer values ranging from 0 to 3 ); $x, y$, and $z$ are the coordinates of the observed anomaly; $x_{0}, y_{0}$, and $z_{0}$ are the coordinates of the edge of the source body; and B is the background value.

The total gradient vector of the potential field $\mathrm{F}$ is called the analytic signal and, in its general formulation [Nabighian, 1972], is a complex number. In the Euler deconvolution method only the real part is used, i.e. the absolute value of the total gradient. For the sake of simplicity, 
we will henceforth use the term analytic signal to refer to only the real part. The analytic signal provides information about the horizontal location of the anomaly source.

Source depth information basically depends on the field curvature, i.e. on the geometry of the source. This information is encapsulated in the SI, which is, in the linear formulation of the problem, an integer number that describes different simplified geometries of the causative body. Although technical manuals distributed with the commercial software suggest the feasibility of non-integer values for the SI, and some authors have applied such values to real data problems [see Reid and Thurston, 2014, for a review], the use of non-integer SI values is considered correct only in the non-linear extension of the Euler's formulation [Stavrev and Reid, 2007]. This is because a non-integer SI is dependent on the distance from the source, while the homogeneity equation requires it to be constant. With this in mind, although the body geometries corresponding to the integer SI are far from being the real geological structures expected in the study area, we adhere to the recommendation of using an integer SI.

In this study are used magnetic anomaly [Bankey et al., 2002] and Bouguer gravity anomaly [Kucks, 1999] data available from the USGS for the continental United States. The spatial resolution of the data is $1 \mathrm{~km}$ and $4 \mathrm{~km}$, respectively. The data have been preprocessed in Cartesian coordinates and upward-continued to an elevation equal to the grid resolution. This operation is effective in suppressing noise and short wavelength contributions, without distortion that could possibly arise from arbitrary bandpass filtering [Lyatski et al., 2005]. The window size used in the search for the source location is kept greater than twice the spatial resolution of the respective dataset and greater than half the desired depth range of investigation, following Reid et al. [2014]. Thus, the analytic signal of the field is computed and processed through Euler deconvolution. Being originally formulated for magnetic anomalies, there are few examples of 
the application of Euler deconvolution to gravity data. The inversion of the gravity anomaly is usually better constrained using the first derivative of the field in place of the field itself [Klingele et al., 1991]; therefore, we also use this approach.

\section{Results and Discussion}

In this section the results of Euler deconvolution of the magnetic anomaly (Fig 2a) are first described. As explained in the previous section, the depth of the source retrieved by the inversion is strongly affected by the choice of the SI, which should be selected based on a priori geological assumptions. However, where the nature of the potential field anomaly is uncertain, restricting its source to a simple geometrical model can be difficult. In the following, we discuss the results obtained using $\mathrm{SI}=1$, i.e. assuming a causative body with two infinite dimensions (e.g. $\mathrm{x}$ and $\mathrm{y}$ or $\mathrm{z}$ and $\mathrm{x}-\mathrm{y}$ ), which is compatible with a thin edge or sill/dyke model. An SI $=0$ (i.e. an infinite contact source) has first been tested but only very shallow solutions were obtained (<4 km depth), mainly in the Blue Ridge, Piedmont, and Cumberland Plateau (i.e. the southern part of Appalachian Plateaus) provinces, while few solutions have been found in the Valley and Ridge province. Furthermore, in an attempt to detect bed fault structures, an SI = 2 has been tested, but without obtaining reliable results. This is likely because strike-slip faults, the prevalent style in the ETSZ, are difficult to detect using Euler deconvolution, which gives the middle point of a finite step and thus is more effective for investigating dip-slip faults [Reid et al., 1990]. The solutions accepted are those with a depth uncertainty $\leq 5 \%$, although features smaller than the grid resolution ( $1 \mathrm{~km}$ for magnetic data) should not be considered reliable.

From the analytic signal the following features are clearly shown: 1) a strong magnetic gradient east of the Appalachians, in the Piedmont and Coastal Plain provinces; 2) the NE-SW trending signature of the Appalachian orogeny east of the Clingman lineament; 3) the NY-AL 
lineament, striking about $35-40^{\circ} \mathrm{N}$ from latitudes $35^{\circ} \mathrm{N}$ to $38^{\circ} \mathrm{N}$, and 4) more to the west, an almost N-S striking signature corresponding to the mottled pattern of magnetic anomaly of the granite-rhyolite province and mafic intrusions (Fig. 2b).

The depth to the source of the magnetic anomaly can be considered the depth to the magnetic basement, i.e. the thickness of the non-magnetic sedimentary cover, although Euler deconvolution actually retrieves the edge of the causative bodies, which is not necessarily coincident with the top of the geological basement.
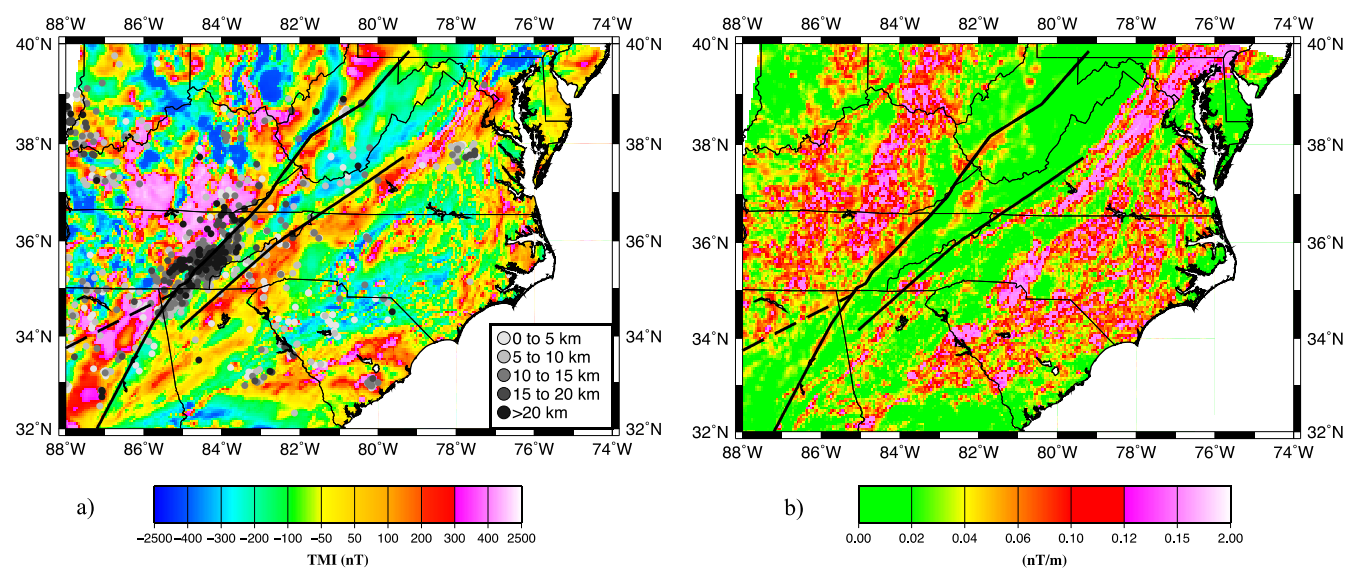

Figure 2. a) Total magnetic anomaly (nT) in the study area. Gray dots are hypocenters reported in the CERI-University of Memphis catalogue from 1974 to 2014. Black lines denote the New York-Alabama (NY-AL) and Clingman (CL) magnetic lineaments. Dashed black line denotes the southern segment of the NY-AL lineament after Steltenpohl et al. [2010]. b) Analytic signal (nT/m) of the magnetic field. For color legend refer to the online version of the paper.

Our results show that the deepest sources are located beneath the Valley and Ridge, where they locally exceed $12 \mathrm{~km}$ depth in the northern and southern part of the province (color circles in Fig. 3), and in the ETSZ in particular, where they range from 4-6 km to 8-12 km 
depth. The Blue Ridge and Piedmont provinces show relatively shallower sources, with local outcrops related to the Appalachian orogeny, while the Cumberland Plateau exhibits intermediate source depths $(2-4 \mathrm{~km})$. The depths of the sources then increase towards the Coastal Plain and the Atlantic passive margin, although the latter area could be influenced by border effects and thus is not included in our interpretation.

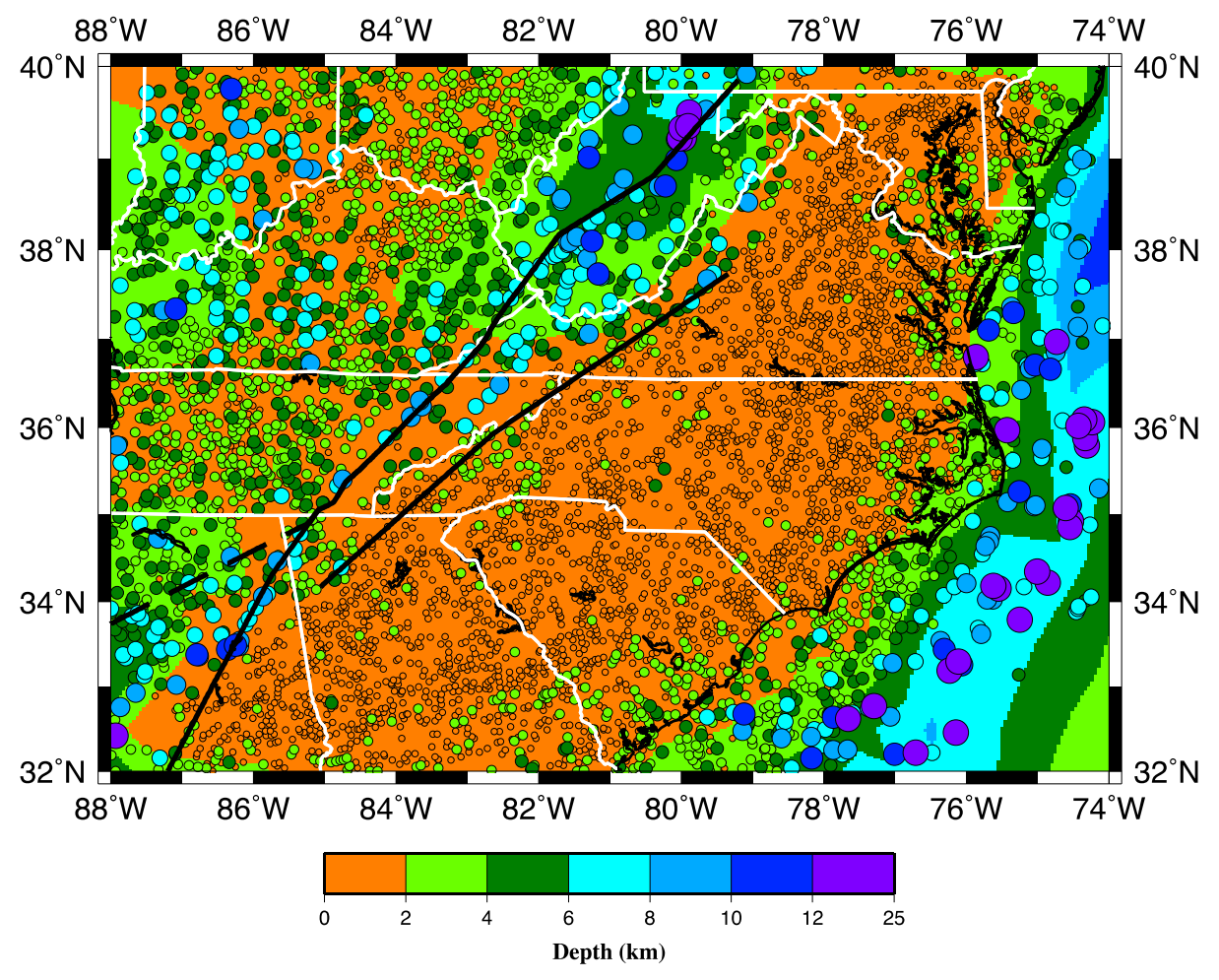

Figure 3. Results of the Euler deconvolution of the magnetic anomaly data, representing the depth to the top of the magnetic basement (circles), superimposed over a map of sediments obtained by seismic data analysis [SEDMAP, Laske and Masters, 1997, color contour]. Black lines denote the New York-Alabama (NY-AL) and Clingman (CL) magnetic lineaments. Dashed black line denotes the southern segment of the NY-AL lineament after Steltenpohl et al. [2010]. For color legend refer to the online version of the paper. 
In order to assess the extent to which our results represent the top of the geological basement, they are compared with a map of sediments [SEDMAP, Laske and Masters, 1997] derived from seismic data analysis (color contour in Fig. 3). However, the sediments are not unambiguously defined in terms of the composing lithologies, and thus by their seismic velocities. For example, in Western Europe, the top of the basement usually corresponds to a $V_{P}$ of 5.4-5.6 km/s, while for most of the East European Platform, where the uppermost crust is characterized by a thick layer of carbonates, it is associated with a $\mathrm{V}_{\mathrm{P}}$ of about $5.8 \mathrm{~km} / \mathrm{s}$ [Artemieva and Thybo, 2013]. The latter value is the one chosen by Chulick et al. [2013] to define the top of the basement in the South American continent, since it is lower than the velocities of most granitic rocks $\left(\mathrm{V}_{\mathrm{P}}>5.9 \mathrm{~km} / \mathrm{s}\right)$. The same value is chosen by many authors for the North American continent [e.g. Chulick and Mooney, 2002; Tesauro et al., 2014]. In SEDMAP, the $\mathrm{V}_{\mathrm{P}}$ of hard sediments is considered to be $<5.3 \mathrm{~km} / \mathrm{s}$, and Paleozoic metamorphosed sediments are included in the upper crystalline crust [Mooney et al., 2010]. The results are generally consistent with SEDMAP at a regional scale, since the pattern of magnetic source depths generally mimics the pattern of sedimentary cover in the area (Fig. 3). Nevertheless, the depths estimated by the two datasets significantly differ in some places, especially in the Valley and Ridge (up to $8 \mathrm{~km}$ locally) and along the Atlantic passive margin. One explanation for this difference could be that the aforementioned sediment definition used in SEDMAP may actually include limestone layers in the crystalline crust. It is also worth noting that the resolution of SEDMAP is $2^{\circ} \times 2^{\circ}$, thus it may not image small-scale lateral heterogeneities resolved by our inversion. Another possible explanation is that the depth to the magnetic basement retrieved by Euler deconvolution could be overestimated due to the constraints posed by the choice of the SI, since solution's depth usually increases with increasing 
SI. We tend to rule out this possibility since this effect should be systematic, but no or little overestimation occurred in the Cumberland Plateau, Blue Ridge, Piedmont, and Coastal Plain. Mooney and Kaban [2010] report a sedimentary cover thickness of about $6 \mathrm{~km}$ beneath the Valley and Ridge, and Graw et al. [2015] estimated, using receiver functions, $\mathrm{V}_{\mathrm{P}}<6 \mathrm{~km} / \mathrm{s}$ down to 8-10 km of the depth along the NY-AL lineament. These values are within the range of our estimate, although Graw et al. [2015] interpret their findings as low velocity basement crust, which is consistent with previous studies that estimated a shallower sedimentary cover in the area [Sodbinow and Bollinger, 1978; Owens et al., 1984].

With respect to gravity data, the ETSZ exhibits a slightly negative anomaly, while the two most prominent features in the study area are the NE-SW trending negative anomaly marking the Appalachian axis east of the ETSZ (Fig. 4a, marked by A), and a strong positive anomaly northwest of the ETSZ (Fig 4a, marked by B), part of a cluster of spotted gravity highs and lows extending through the Inner and Central Lowlands and likely related to Proterozoic rifting [Powell et al., 2014].

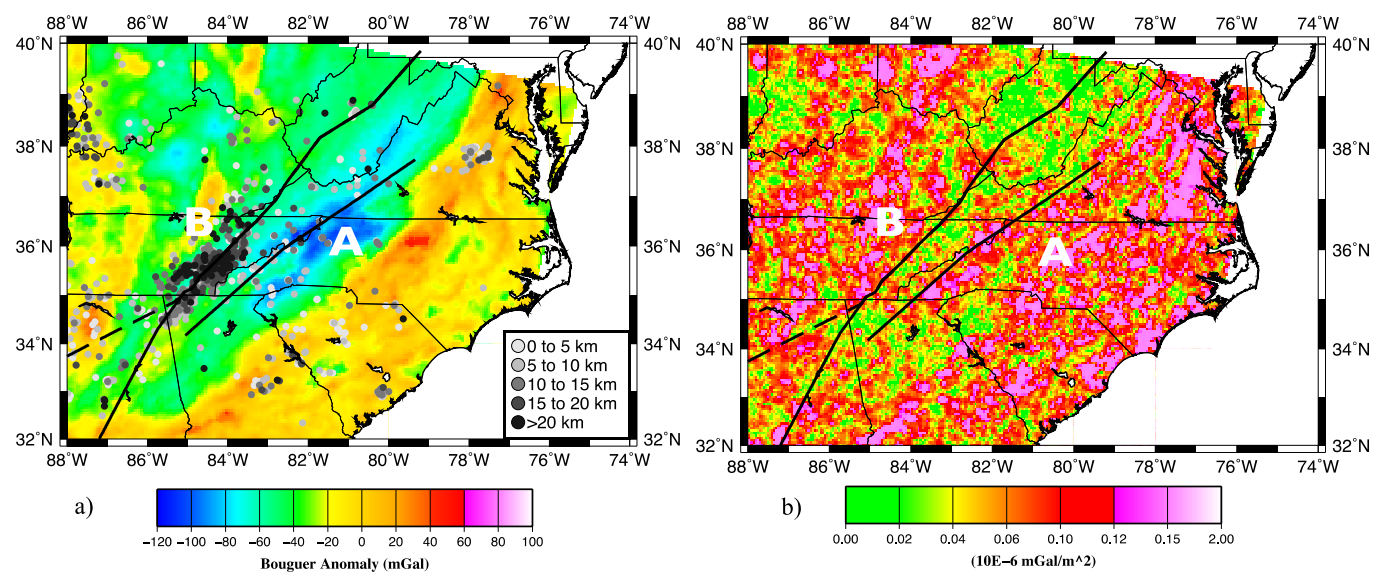

Figure 4. a) Bouguer gravity anomaly (mGal) in the study area. Gray dots are hypocenters reported in the CERI-University of Memphis catalogue from 1974 to 2014. Black lines denote 
New York-Alabama (NY-AL) and Clingman (CL) magnetic lineaments. Dashed black line denotes the southern segment of the NY-AL lineament after Steltenpohl et al. [2010]; b) analytic signal $\left(10^{-6} \mathrm{mGal} / \mathrm{m}^{2}\right)$ of the vertical derivative of the gravity field (pseudomagnetic field). Capital letters denote features referred to in the text. For color legend refer to the online version of the paper.

Gravity anomaly data, upward-continued to the grid spacing (i.e. $4 \mathrm{~km}$ ), have been first inverted using an SI = 0, appropriate for a thin sheet edge model. The results of this inversion did not reveal any significant structures for the ETSZ, as the only feature resolved was a NE-SW trending line of sources likely corresponding to the Brevard fault. This could be related to the lower resolution of the gravity data compared to the magnetic data. Thus, we tried to resolve deep-seated basement fault structures using an SI = 1, appropriate for modeling thin bed faults, but this trial also failed to provide satisfactory results for the ETSZ. This could stem from the prevalent strike-slip faulting style in the ETSZ [Chapman et al., 1997; Cooley, 2015], while Euler deconvolution is more effective for detecting dip-slip faults, as it retrieves the depth marking the half point of the vertical offset between two fault blocks, provided that the depth to the fault significantly exceeds the fault thickness [Reid et al., 1990].

Finally, the vertical gradient of the gravity field, also known as the pseudomagnetic field, has been inverted using an $\mathrm{SI}=1$ (the same as used for the magnetic field), since this approach usually gives better results than inverting the field itself [Klingele et al., 1991]. In this case depth uncertainty threshold for accepted solutions is $\leq 10 \%$. As can be seen in the analytic signal map (Fig. 4b), the NY-AL lineament does not show a specific gravity signature, and the pseudomagnetic field gradient is quite variable along the strike. The Tennessee segment of the 
216 lineament exhibits a strong gradient on the NW side, while this pattern appears to be reversed

217 across Georgia and Virginia. However, the entire Valley and Ridge province is characterized by

218 a low gradient.
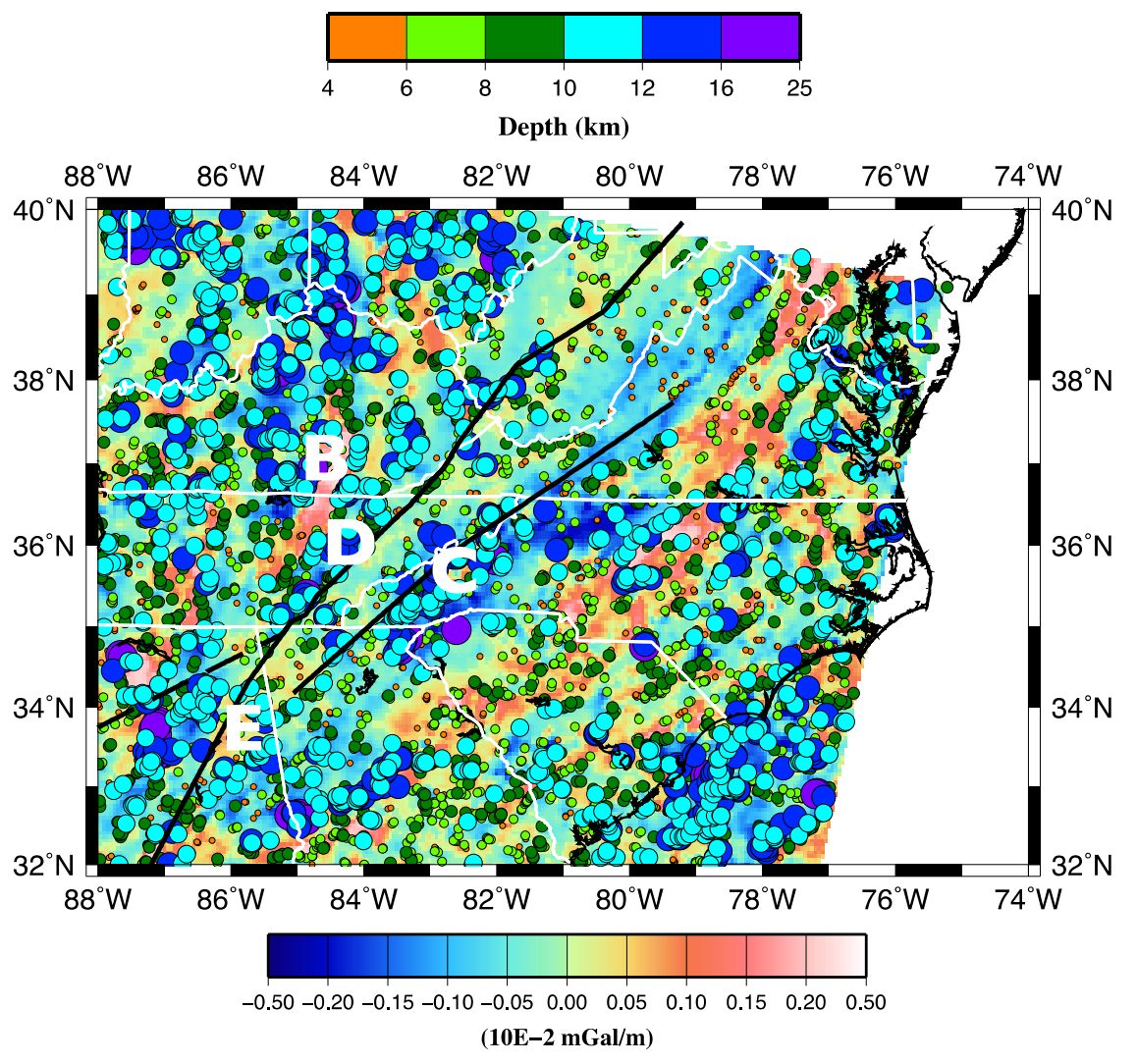

220 Figure 5. Results of the Euler deconvolution of the vertical derivative of the gravity field

221 (pseudomagnetic field), representing the depth to the source of the gravity anomaly (circles)

222 superimposed over the map of the gravity field vertical derivative $\left(10^{-2} \mathrm{mGal} / \mathrm{m}\right)$. Black lines

223 denote the New York-Alabama (NY-AL) and Clingman (CL) magnetic lineaments. Dashed

224 black line denotes the southern segment of the NY-AL lineament after Steltenpohl et al. [2010].

225 Letters denote features discussed in the text. For color legend refer to the online version of the 226 paper. 
The results of the gravity inversion are ambiguous, difficult to interpret and challenging

to compare to the magnetic data. Generally, all causative bodies lie several kilometers deeper than those causing the magnetic anomaly, so the relation between them is not obvious. The clearest features are basement linear structures oriented roughly NE-SW along the Clingman lineament (Fig. 5, marked by C) and the NY-AL lineament (Fig. 5, marked by D), mostly located at depths between $10 \mathrm{~km}$ and $16 \mathrm{~km}$. The positive anomaly NW of the NY-AL lineament probably represents a Proterozoic rift (B, Fig. 4a and 5) and likely originates at a depth of 8-12 $\mathrm{km}$, although this intrusion has been drilled [Fisher et al., 2010] thus its top is at least locally surely shallower than that. Similar depths are retrieved for another positive anomaly to the SE of the NY-AL lineament, in northern Alabama (Fig. 5, marked by E). If this anomaly is caused by mafic rocks with the same tectonic origin as the ones NW of the lineament, our findings could support the interpretation of the NY-AL lineament as an intra-Grenville feature. The shallowest sources are found beneath the eastern Piedmont and the Coastal Plain (4-6 km) and are mainly associated with positive gradients of the pseudomagnetic field.

Based on the overall results, we interpret the depth to magnetic sources as representative of the top of the basement or its proximity. Following this interpretation, the sedimentary cover in the Valley and Ridge and the ETSZ would be significantly thicker than what previous studies report, although the possibility that intra-basement sources associated with compositional changes can be a cause of the deepest sources found cannot be ruled out. This second hypothesis, which could help explain the occurrence of seismicity, needs additional seismological investigation and more accurate gravity data in order to better constrain lithologies in the upper crust. A companion paper shows the results of seismic noise tomography in the ETSZ, from which a pronounced low velocity zone is imaged at depths where seismicity occurs, roughly 
251 bounded between the NY-AL and Clingman lineaments. A low velocity zone was already

252 detected beneath the projection of the NY-AL lineament by Powell et al. [2014] via local

253 earthquake tomography. The earthquakes occur on the margin of the low velocity zone, which

254 Powell et al. [2014] interpret as a reactivated sheared basement block bounded by a large-scale

255 transform fault between Amazonia and proto-Laurentia during the Mesoproterozoic assembly of

256 Rodinia [Powell and Thomas, 2015]. The investigation of the relationship between this low

257 velocity anomaly and the sources of magnetic and gravity anomaly is out of the scope of this

258 paper.

Steltenpohl et al. [2010] suggested an affinity between the Ocooe block basement and the Amish anomaly, located in the state of New York, mainly composed of relatively non-magnetic metasedimentary rocks. This hypothesis is not supported by our results that show that the seismogenic part of the Ocooe block lies beneath the magnetic basement. Consequently, we speculate that the relatively low magnetic and gravity anomalies associated with the Ocooe block could be ascribed to thick sedimentary cover.

Although most of the sources of the gravity anomalies in the ETSZ lie in the same range of depths at which seismic activity occurs, the results of the inversion are still poorly constrained due to low data resolution. Furthermore, a wide range of rocks exposed in the Blue Ridge and 268 likely composing the seismogenic zone, including granite gneisses, felsic to mafic granulite 269 gneisses, and paragneisses, are compatible with low magnetic and gravity field anomalies $270 \quad$ [Powell and Thomas, 2015]. 
274 [2007], and thin flow intrusions are both compatible with the SI used for the magnetic inversion.

275 Thus, the origin of this lineament is yet to be unraveled.

\section{Conclusions}

In this study magnetic and gravity data for the ETSZ and its vicinity have been inverted using the Euler deconvolution method. The inversion of magnetic data by means of Euler deconvolution is effective in identifying the top of the basement and proves to be useful not only for exploration geophysics but also for tectonic investigation where seismic data are sparse or not available. The inversion of gravity data is much more ambiguous, likely due to poor resolution of the data.

The top of the magnetic basement ranges between 6 and $12 \mathrm{~km}$ depth in the Valley and Ridge physiographic province, while it is shallower $(<2 \mathrm{~km}$ depth) and locally outcropping in the Blue Ridge and in the Cumberland Plateau provinces.

The seismic activity in the ETSZ is mainly located in a basement block bounded to the NW by the NY-AL lineament and to the SE by the Clingman lineament. Our findings support the interpretation of ETSZ seismicity as originating in Grenville age basement structures that are not related to Appalachian orogen. Better understanding of the seismic structure of the ETSZ needs further gravity data analysis combined with detailed seismic velocity models.

\section{Acknowledgments}

We deeply acknowledge Dr. Christine Powell and another anonymous reviewer for their thoughtful comments and useful suggestions that greatly improved our manuscript. This work was supported by National Science Foundation CREST award number 1345219. Any opinions, findings, and conclusions or recommendations expressed in this study are those of the authors 
and do not necessarily reflect the views of the National Science Foundation. Inversion was carried out using Geosoft Oasis Montaj ${ }^{\circledR}$ software. Figures have been plotted using GMT (Generic Mapping Tools; Wessel and Smith, 1995).

\section{References}

Artemieva, I.M., and H. Thybo (2013), Moho discontinuity and crustal structure in Europe, Greenland, and the North Atlantic region. Tectonophysics 609, 97-153.

Bankey, V., Cuevas, A., Daniels, D., F., Carol A., Hernandez, I., Hill, P., Kucks, R., Miles, W., Pilkington, M., Roberts, C., Roest, W., Rystrom, V., Shearer, S., Snyder, S., Sweeney, R., Velez, J., Phillips, J.D., and D. Ravat (2002), Digital data grids for the magnetic anomaly map of North America: U.S. Geological Survey Open-File Report 02-414, U.S. Geological Survey, Denver, Colorado, USA.

Bollinger, G. A. (1973). Seismicity of the southeastern United States. Bulletin of the Seismological Society of America, 63(5), 1785-1808.

Bollinger, G. A., Langer, C. J., and S.T., Harding (1976), The eastern Tennessee earthquake sequence of October through December, 1973. Bulletin of the Seismological Society of America, 66(2), 525-547.

Chapman, M.C., Powell, C.A., Vlahovic, G., and M.S. Sibol (1997), The nature of faulting in eastern Tennessee inferred from a statistical analysis of focal mechanisms and epicenter locations: Bulletin of the Seismological Society of America, v. 87, p. 1522-1536.

Chulick, G. S., and W. D. Mooney (2002), Seismic structure of the crust and uppermost mantle of North America and adjacent oceanic basins: a synthesis. Bulletin of the Seismological Society of America, 92(6), 2478-2492. 
Chulick, G.S., Detweiler, S., and W.D. Mooney (2013), Seismic structure of the crust and uppermost mantle of South America and surrounding oceanic basins. J. S. Am. Earth Sci. $42,260-276$.

Cooley, M.T. (2015), A new set of focal mechanisms and a geodynamic model for the eastern Tennessee seismic zone [M.S. thesis]: Memphis, Tennessee, The University of Memphis, $46 \mathrm{p}$.

Dunn, M. M., and M. C. Chapman (2006), Fault orientation in the eastern Tennessee seismic zone: A study using the double-difference location algorithm, Seismol. Res. Lett., 77, 494-504.

Fenneman, N. M., and D. W. Johnson (1946), Physiographic divisions of the conterminous U. S.

Fisher, C. M., S. L. Loewy, C. F. Miller, P. Berquist, W. R. Van Schmus, R. D. Hatcher Jr., J. L. Wooden, and P. D. Fullagar (2010), Whole-rock Pb and Sm-Nd isotopic constraints on the growth of southeastern Laurentia during Grenvillian orogenesis, Geol. Soc. Am. Bull., 122, 1646-1659,doi:10.1130/B30116.1.

Graw, J. H.,C.A. Powell, and C.A. Langston (2015), Crustal and upper mantle velocity structure in the vicinity of the eastern Tennessee seismic zone based upon radial $\mathrm{P}$ wave transfer functions, J. Geophys. Res. Solid Earth, 120, 243-258, doi:10.1002/2014JB011516.

Hopkins, D.L. (1995), The New York-Alabama Magnetic Lineament: Its reflection character and relationship to the Grenville Front [Ph.D. thesis]: Blacksburg, Virginia Polytechnic Institute and State University, $176 \mathrm{p}$.

Johnston, A.C., Reinbold, D.J., and S.I. Brewer (1985), Seismotectonics of the Southern Appalachians: Seismological Society of America Bulletin, v. 75, p. 291-312. 
King, E. R., and I. Zietz (1978), The New York-Alabama lineament: Geophysical evidence for a major crustal break in the basement beneath the Appalachian Basin, Geology, 6, 312318.

Klingele E.E., Marson I. and H.G. Kahle (1991), Automatic interpretation of gravity gradiometric data in two dimensions: vertical gradient. Geophysical Prospecting 39, 407434.

Kucks, R. P. (1999), Bouguer gravity anomaly data grid for the conterminous US.

Laske, G., and G. Masters (1997), A global digital maps of sediment thickness. Eos, Trans. Am. Geophys. Union 78 F483

Lyatsky, H. V., Pană, D. I., and M. Grobe (2005), Basement structure in central and southern Alberta: Insights from gravity and magnetic maps. Alberta Energy and Utilities Board: Alberta Geological Survey.

Mooney, W. D., and M. K. Kaban (2010), The North American upper mantle: Density, composition, and evolution, J. Geophys. Res., 115, B12424, doi:10.1029/2010JB000866.

Nabighian, M. N. (1972), The analytic signal of two-dimensional magnetic bodies with polygonal cross-section: Its properties and use for automated anomaly interpretation: Geophysics, 37, 507-517.

Owens, T. J., G. Zandt, and S. R. Taylor (1984), Seismic evidence for an ancient rift beneath the Cumberland Plateau, Tennessee: A detailed analysis of broadband teleseismic P waveforms, J. Geophys. Res., 89, 7783-7795, doi:10.1029JB089iB09p07783.

Powell, C. A., and W.A. Thomas (2015), Grenville basement structure associated with the Eastern Tennessee seismic zone, southeastern USA.Geology, G37269-1. 
362 Powell, C. A., G. A. Bollinger, M. C. Chapman, M. S. Sibol, A. C. Johnson, and R. L. Wheeler (1994), A seismotectonic model for the 300 kilometer long eastern Tennessee seismic zone, Science, 264, 686-688.

Powell, C.A., Withers, M., Cox, R.T., Vlahovic, G., and P. Arroucau (2014), Crustal velocity structure associated with the eastern Tennessee seismic zone: Vp and Vs images based upon local earthquake tomography: Journal of Geophysical Research, v. 119, p. 464-489, doi:10.1002/2013JB010433.

Reid A.B., Allsop J.M., Granser H., Millet A.J., and I.W. Somerton (1990), Magnetic interpretation in three dimensions using Euler deconvolution. Geophysics 55, 80-91.

Reid, A. B., and J.B. Thurston, (2014), The structural index in gravity and magnetic interpretation: Errors, uses, and abuses. Geophysics, 79(4), J61-J66.

Sodbinow, E. S., and G. A. Bollinger (1978), Seismic studies in central and eastern Tennessee, Bull. Seismol. Soc. Am., 68, 1081-1094.

Stavrev P., and A.B. Reid (2007), Degrees of homogeneity of potential fields and structural indices of Euler deconvolution. Geophysics 71, L1-L12.

Steltenpohl, M. G., Zietz, I., Horton, J. W., and D.L. Daniels (2010), New York-Alabama lineament: A buried right-slip fault bordering the Appalachians and mid-continent North America. Geology, 38(6), 571-574.

Tesauro, M., Kaban, M. K., Mooney, W. D., and S. Cloetingh (2014), NACr14: A 3D model for the crustal structure of the North American Continent. Tectonophysics, 631, 65-86.

Thomas, W. A. (2006), Tectonic inheritance at a continental margin, GSA Today, 16(2), 4-11, doi:10.1130/1052-5173(2006)016<4:TIAACM>2.0.CO;2. 
384 Thompson D.T. (1982), EULDPH - A new technique for making computer assisted depth estimates from magnetic data. Geophysics 47, 31-37.

386 Vlahovic, G., C. A. Powell, M. C. Chapman, and M. S. Sibol (1998), ET1D: New one

387 dimensional P- and S-wave velocity models for the eastern Tennessee seismic zone, $388 \quad$ Seismol. Res. Lett., 69(5), 441-449.

389 Wessel, P., Smith, W. H., Scharroo, R., and J.M. Luis (2011), The Generic Mapping Tools (GMT) Version 5. In AGU Fall Meeting Abstracts (Vol. 1, p. 05).

391 Whitmeyer, S. J., and K.E., Karlstrom, (2007), Tectonic model for the Proterozoic growth of $392 \quad$ North America. Geosphere, 3(4), 220-259. 